\title{
Symptom-histopathology relation in upper GI endoscopy
}

\author{
Emre Günay, Erkan Özkan, Hacı Mehmet Odabașı, Hacı Hasan Abuoğlu, Cengiz Eriş, Mehmet Kamil Yıldız, Süleyman Atalay
}

Objective: The purpose of this article is to examine the correlation between information obtained from patients before endoscopy and histopathological findings.

Material and Methods: One thousand, five hundred and thirty-six patients underwent upper $\mathrm{Gl}$ endoscopy between January 2011-September 2012, without distinction of age and sex were included in the study. Patients with alarm symptoms, dyspepsia, epigastric pain, gastroesophageal reflux were recorded. Tissue samples taken for histopathological examination and $H$. pylori screening were evaluated by Giemsa stain. The information given by the patients and histopathological findings were comparatively evaluated.

Results: Six hundred and twenty-four patients (40.6\%) were male and 912 (59.4\%) were female. Mean age was 45 years (18-90). H. pylori was positive in 416 patients with dyspepsia (58.8\%), 172 patients with epigastric pain (54.4\%), 52 patients with GER symptoms (28.3\%) and 128 patients with alarm symptoms (50.8\%). Four patients with dyspepsia $(0.6 \%)$ and 20 patients with alarm symptoms $(7.9 \%)$ were diagnosed with stomach cancer.

Conclusion: The main factor should be considered as the presence of at least one of the alarm symptoms when planning an upper $\mathrm{Gl}$ endoscopy in a patient. In the presence of at least one of the alarm symptoms, an upper $\mathrm{Gl}$ endoscopy should be performed regardless of age. Under the age of 50 and for patients without alarm symptoms, medical treatment can be tried before performing upper GI endoscopy. Patients with GER symptoms but not diagnosed as reflux esophagitis, should be treated long-term even when symptoms decline with initial treatment.

Key Words: Endoscopy, gastroscopy, H. pylori, gastric cancer, alarm symptoms

Haydarpaşa Numune Teaching Hospital, Department of General Surgery, Istanbul, Turkey

\section{Address for Correspondence Dr. Emre Günay}

Haydarpaşa Numune Teaching Hospital, Department of General Surgery, Istanbul, Turkey Phone: +90 2164144502 e-mail:

emregunay2000@yahoo.com

Received: 14.06 .2013

Accepted: 17.08.2013

CCopyright 2013 by Turkish

Surgical Association

Available online at

www.ulusalcerrahidergisi.org

\section{INTRODUCTION}

The increase in daily-performed endoscopy numbers and complications necessitate high quality patient history taking. Endoscopy is the primary diagnostic tool in patients older than 50 years with complaint of epigastric pain. Advanced age and the presence of alarm symptoms (dysphagia, vomiting, gastrointestinal bleeding, anemia, loss of appetite and weight loss) may suggest malignancy (1). In addition, younger patients presenting with alarm symptoms should also undergo endoscopy. Medical treatment can be chosen initially for these young patients. Some centers only plan endoscopy if the patient is diagnosed with $\mathrm{H}$. pylori infection and if the symptoms continue after treatment. This study aims to evaluate the correlation between patient history and endoscopic histopathology findings.

\section{MATERIAL AND METHODS}

All 1536 patients who underwent an upper GI endoscopy between January 2011-September 2012 were included, regardless of age and gender. Complaints of alarm symptoms, dyspepsia, epigastric pain, gastro-oesophageal reflux (GER) were recorded. Tissue samples were evaluated by Giemsa stain for histopathological examination and $H$. pylori screening. The information given by the patients prior to endoscopy were compared to endoscopic histopathology findings. Due to the retrospective nature of the study informed consent for this publication was not taken, informed consent for the endoscopic procedures had already been taken prior to the procedures. An ethical board review was obtained from Haydarpaşa Numune Teaching Hospital Ethics Committee with the approval ID of HNEAH-KAEK 2013/34 (HNEAH-KAEK 2013/KK/34).

\section{Statistical Analysis}

Analyses were done by using Number Cruncher Statistical System (NCSS) 2007\&PASS (Power Analysis and Sample Size) 2008 Statistical Software (Utah, USA). Descriptive statistics (mean, standard deviation, median, frequency, and ratio) were used as well as chi-square test for single cell evaluations. A p value of $\mathrm{p}<0.05$ was accepted as significant. 


\section{RESULTS}

Six hundred twenty four patients were male (40.6\%) and

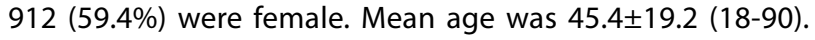
Seven hundred eight patients received upper GI endoscopy (46.1\%) for dyspepsia (112 patients with dyspepsia unresponsive to medical treatment), 316 (20.6\%) for epigastric pain, $184(12 \%)$ for gastro-oesophageal reflux symptoms and 252 (16.4\%) for alarm symptoms (132 of this group for iron deficiency anemia and 36 for presence of blood in stool). Thirty-six patients receiving treatment for $\mathrm{H}$. pylori (1.8\%), 28 patients who had a gastrectomy for gastric cancer (\%1.8) and 12 patients who were operated for peptic ulcer perforation (\%0.8) received upper $\mathrm{Gl}$ endoscopy for follow-up. H. pylori was detected in 416 patients with dyspepsia (58.8\%), in 172 patients with epigastric pain (54.4\%), in 52 patients with GER symptoms (28.3\%) and in 128 patients with alarm symptoms (50.8\%). Dyspeptic complaints and $H$. pylori positivity showed a statistically significant correlation with chi-square test as shown both in Table 1 and Figure 1. Four patients with dyspepsia $(0.6 \%)$ and 20 patients with alarm symptoms (7.9\%) were diagnosed with gastric cancer, whereas gastric cancer was not detected in any of the approximately 500 patients with complaints of epigastric pain or GER symptoms. Four patients who presented with dyspeptic symptoms but were diagnosed with gastric cancer (adenocarcinoma) in upper $\mathrm{Gl}$ endoscopy were all negative for $H$. pylori. In 20 patients who presented with alarm symptoms and gastric malignancy was detected, 18 patients had adenocarcinoma and 2 malignant lymphoma. H. Pylori was positive in all patients with malignant lymphoma and in 4 out of 18 patients with adenocarcinoma. Correlation between gastric cancer and $H$. pylori are depicted in Table 2 and Figure 2. Reflux oesophagitis was diagnosed in 24 patients who presented with dyspeptic complaints, 12 of which were positive for $H$. pylori. Eight patients presenting with epigastric pain had reflux oesophagitis, 4 of which were positive for H. pylori. None of the patients with complaints of GER or alarm symptoms were diagnosed with reflux oesophagitis.

\section{DISCUSSION}

Therapy against $H$. pylori eradication without performing an upper Gl endoscopy is a valid option for patients with complaints of dyspepsia and epigastric pain, if they are younger than 50 and are not pre-diagnosed with cholelithiasis. In this group, therapy is based on elimination of $H$. pylori infection and gastric acid inhibition by proton pump inhibitors (2). Nonetheless, if symptoms persist after such treatment an upper Gl endoscopy must be planned.

We routinely perform upper $\mathrm{Gl}$ endoscopy for all patients with alarm symptoms regardless of age or gender and biopsy the antral mucosa even when a major pathology is not encountered. Follow-up endoscopy was planned for verification of eradication in patients with histopathologically proven $H$. pylori infection.

Routine follow-up endoscopy is not recommended for patients with alarm symptoms if the initial endoscopy was normal. However, there isn't enough data regarding the results of this suggestion (3). In the August 2004 guideline published by United Kingdom Secretary of Health, empiric treatment with antisecretory drugs are suggested, reserving endoscopy only for the presence of alarm symptoms (4).

Wegman (5) analyzed diagnostic value of endoscopy in detection of H. Pylori in Turkish descent male and female immigrants.

Table 1. The relationship between indication for Upper GI endoscopy and H.pylori

\begin{tabular}{|c|c|c|c|}
\hline $\begin{array}{l}\text { Indication for Upper } \\
\text { GI Endoscopy }\end{array}$ & H. pylori (+) & H. pylori (-) & $\mathrm{p}$ \\
\hline Dyspeptic Complaints ( $n=708$ & 416 (58.8\%) & $292(41.2 \%)$ & $0.001^{* *}$ \\
\hline Epigastric Pain $(n=316)$ & $172(54.4 \%)$ & $144(45.6 \%)$ & 0.115 \\
\hline GER Symptoms ( $n=184)$ & 52 (28.3\%) & 132 (71.7\%) & $0.001^{* *}$ \\
\hline Alarm Symptoms ( $\mathrm{n}=252)$ & $128(50.8 \%)$ & $124(49.2 \%)$ & 0.801 \\
\hline${ }^{*}$ Control Patients $(n=76)$ & 24 (31.6\%) & $52(68.4 \%)$ & $0.001^{* *}$ \\
\hline
\end{tabular}

Single-cell evaluation chi square test ${ }^{* *} \mathrm{p}<0.01$

*36 patients receiving therapy for $H$. pylori, 28 patients who had undergone gastrectomy for gastric cancer and 12 patients who had an operation for peptic ulcer perforation

Table 2. The relationship between gastric cancer and H.pylori

\begin{tabular}{|lcc|} 
& H. pylori $(+)$ & H.pylori $(-)$ \\
\hline Gastric cancer present $(\mathrm{n}=22)$ & $4(\% 18.2)$ & $18(\% 81.8)$ \\
\hline Gastric cancer absent $(\mathrm{n}=1514) 770(\% 50.9)$ & $744(\% 49.1)$ \\
\hline
\end{tabular}

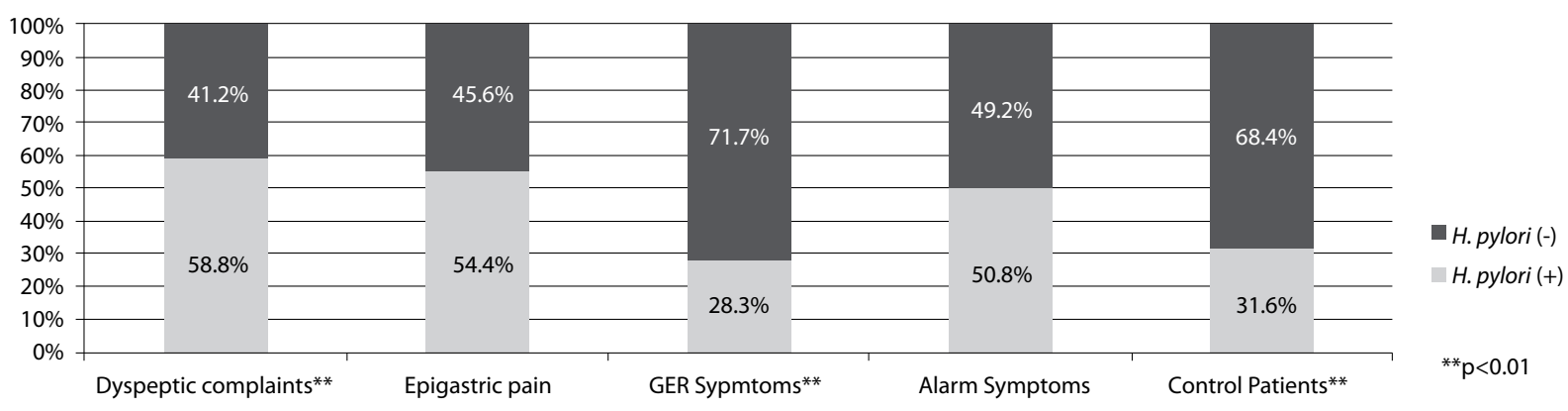

Figure 1. The relationship between Upper GI Endoscopy Indication and H. pylori 


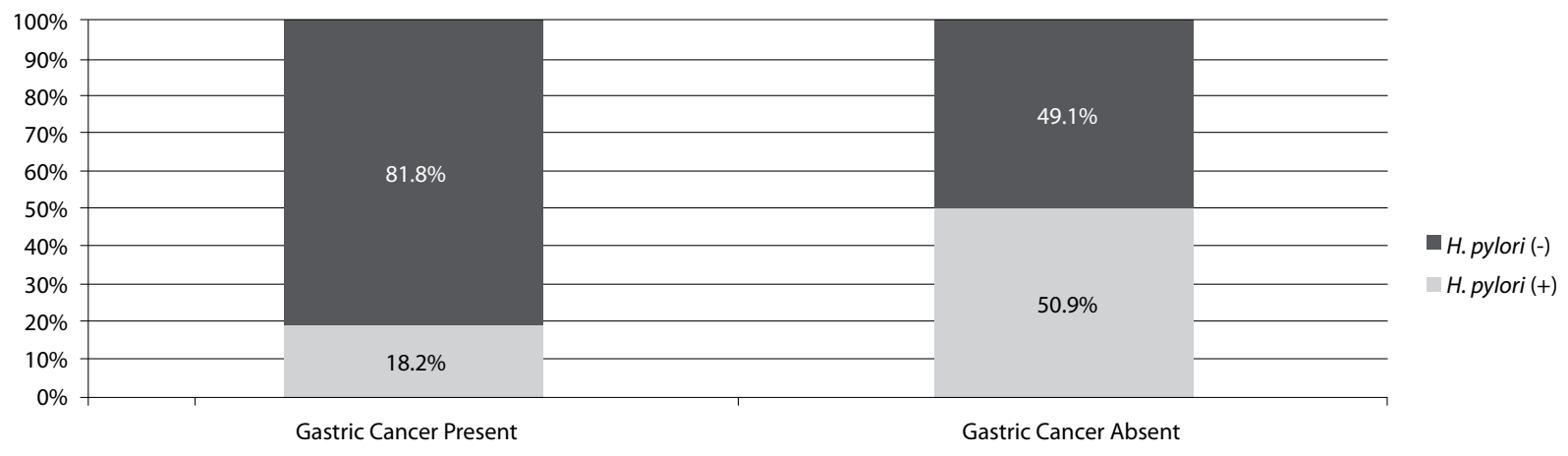

Figure 2. The relationship between Gastric Cancer and H. pylori

We routinely perform endoscopy for patients with cholelithiasis before surgery. These patients are enclosed within the group of patients with complaint of epigastric pain, since the main accepted indication for cholecystectomy in our clinics is abdominal pain.

Like this study protocol, another study has also accepted endoscopy as a first-line diagnostic tool in patients with dysphagia, weight loss, loss of appetite and anemia like alarm symptoms. Endoscopic biopsy is the gold standard for gastric cancer diagnosis, with false negativity rates reported to be as high as $19 \%$ (6). Therefore if a highly suspicious lesion on endoscopy does not show malignancy after histopathology evaluation of the biopsy specimen, this situation should lead us to a repeat endoscopy with multiple second round biopsies. The presence of at least one of the alarm symptoms either together with dyspeptic complaints and epigastric pain or alone by itself increase the risk of gastric cancer from $0,6 \%$ to $7.9 \%$ regardless of age, thus creating an absolute indication for upper $\mathrm{Gl}$ endoscopy. A study from Oxford reported 74 (0.75\%) gastric cancer patients among 9764 endoscopies from 2005 to 2008, 68 of these $(91.9 \%)$ were patients who had presented with alarm symptoms (6). Fransen et al. (7) reported that the mean prevalence of gastric cancer in patients undergoing endoscopy for alarm symptoms was $2.8 \%$. On the other hand, Boldys et al. (8) did not find age or alarm symptoms to be significant factors for upper gastrointestinal endoscopy requirement, at least in regions where gastric cancer prevalence is high. Their series from Poland, with a mean age of 44, revealed 83 gastric cancers (12 early stage, 71 advanced stage) out of 860 endoscopy patients.

In contrast to reports by Kato (9) and Rathbone (10) regarding the correlation between gastric cancer and $\mathrm{H}$. pylori and many other similar reports, in our country there is a strong debate on whether this correlation between $\mathrm{H}$. pylori and gastric cancer is losing importance in time or if this is a mis-perception related to the overall decrease in gastric cancer incidence.

In this study out of the 1536 patients who had an upper Gl endoscopy due to various symptoms 24 (1.6\%) were diagnosed with gastric cancer, 6 of them tested positive for $H$. pylori. Four of these six patients had adenocarcinoma and two had malignant lymphoma on histopathology examination. Patients with malignant lymphoma were positive for $H$. pylori. Andriani et al. (11) showed significant relation between gastric lymphoma and H.pylori.

In order to define patients with gastro-oesophageal reflux disease (GERD) the proton pump inhibitor test can be used, even if the success is limited. Although this approach is questionable, if the patient's symptoms are related to gastric acid and if they have GERD, this may be a tool to assess the efficacy of proton pump inhibitor treatment (PPI) (12). Grande et al. (13) evaluated 215 patients with GERD between 2005-2007, 148 patients did not have any signs of oesophagitis and 67 had mild oesophagitis due to reflux (Savary-Miller classification grade I-II). GERD is associated with oesophagus erosion, ulceration, stricture and Barrett oesophagus. Reflux related symptoms and lesions do not always co-exist; $30-70 \%$ of patients with typical symptoms did not show any signs of oesophagitis on endoscopy(14). None of the patients presenting with GER symtoms had reflux oesophagitis in our study. That is why, non-erosive reflux disease and erosive oesophagitis represent the two most common clinical features of gastro- oesophageal reflux disease. Most of the patients with classical reflux signs do not reveal endoscopic signs of oesophagitis. This group of patients is considered as a mild form of gastrooesophageal reflux disease (13). A commonly shared idea by many investigators is that the incidence of symptoms does not differ according to the presence or absence of oesophagitis in gastro- oesophageal reflux disease patients $(15,16)$. Thus, we can neither accept nor deny the presence of oesophagitis in addition to reflux, relying solely on symptomatology. In a previously discussed study, patients who presented with typical gastro- oesophageal reflux disease symptoms and who did not carry alarm signs were treated empirically without evaluating for oesophageal mucosal damage. Symptoms resolved in only $25 \%$ of patients who did not have oesophagitis and who responded to PPI treatment without antireflux treatment (17). In light of these findings, we can argue that in most patients without oesophagitis long-term treatment is required even if the initial treatment results in symptom relief.

\section{CONCLUSION}

Based on the study findings we concluded that when planning an upper $\mathrm{Gl}$ endoscopy, the main factor to be considered is the presence of at least one of the alarm symptoms. Presence of at 
least one of the alarm symptoms is an absolute indication for upper Gl endoscopy regardless of age. Medical treatment can be used prior to upper $\mathrm{Gl}$ endoscopy in patients younger than 50 years and patients without alarm symptoms. Patients with GER symptoms but who were not diagnosed with reflux oesophagitis on endoscopy should receive long-term treatment even if their symptoms resolve after initial therapy. In a carefully selected group of patients, who have symptoms associated with resistant reflux and does not have endoscopic signs of oesophagitis, surgery should be considered among other management options.

Conflict of Interest: No conflict of interest was declared by the authors.

Peer-review: Externally peer-reviewed.

Ethics Committee Approval: Ethics committee approval was received for this study from the ethics committee of Haydarpaşa Numune Training and Research Hospital Clinical Research Ethics Committee.

Author Contributions: Concept - E.G., E.Ö.; Design - E.G., M.K.Y.; Supervision - H.M.O., C.E.; Funding - E.G., H.H.A.; Materials - S.A.; Data Collection and/or Processing - E.G.; Analysis and/or Interpretation - E.G., E.Ö., H.M.O., M.K.Y.; Literature Review - E.G., S.A., E.Ö., C.E.; Writer - E.G.; Critical Review - E.G., E.Ö., H.M.O.; Other - E.G., H.H.A., C.E., S.A.

\section{REFERENCES}

1. Salo M. Age, symptoms and upper gastrointestinal malignancy in primary care endoscopy. Scand J Gastroenterol 2008; 43: 122-127. [CrossRef]

2. Konturek PC, Brzozowski T, Konturek SJ. Stress and the gut: pathophysiology, clinical consequences, diagnostic approach and treatment options. J Physiol Pharmacol 2011; 62: 591-599.

3. Oksanen $A$. Role of earlier gastroscopy in predicting findings on repeat gastroscopy in a population with a low $\mathrm{H}$. pylori prevalence. Scand J Gastroenterol 2008; 43: 1044-1049. [CrossRef]

4. Bowrey DJ, Griffin SM, Wayman J, Karat D, Hayes N, Raimes SA. Use of alarm symptoms to select dyspeptics for endoscopy causes patients with curable esophagogastric cancer to be overlooked. Surg Endosc 2006; 20: 1725-1728. [CrossRef]
5. Wegman Al. Gastroscopy in immigrants of Turkish descent. J Gastroenterol Hepatol 2009; 24: 1187-1190. [CrossRef]

6. Vradelis S, Maynard N, Warren BF, Keshav S, Travis SP. Quality control in upper gastrointestinal endoscopy: detection rates of gastric cancer in Oxford 2005-2008. Postgrad Med J 2011; 87: 335-339. [CrossRef]

7. Fransen GA, Janssen MJ, Muris JW, Laheij RJ, Jansen JB. Metaanalysis: the diagnostic value of alarm symptoms for upper gastrointestinal malignancy. Aliment Pharmacol Ther 2004; 20: 10451052. [CrossRef]

8. Bołdys H, Marek TA, Wanczura P, Matusik P, Nowak A. Even young patients with no alarm symptoms should undergo endoscopy for earlier diagnosis of gastric cancer. Endoscopy 2003; 35: 61-67. [CrossRef]

9. Kato M. Recent knowledge of the relationship between Helicobacter pylori and gastric cancer and recent progress of gastroendoscopic diagnosis and treatment for gastric cancer. Jpn J Clin Oncol 2010; 40: 828-837. [CrossRef]

10. Rathbone M. Helicobacter pylori and gastric cancer. Recent Results Cancer Res 2011; 185: 83-97. [CrossRef]

11. Andriani A, Zullo A, Di Raimondo F, Patti C, Tedeschi L, Recine $U$, et al. Clinical and endoscopic presentation of primary gastric lymphoma: a multicentre study. Aliment Pharmacol Ther 2006; 23 : 721-726. [CrossRef]

12. Bytzer $P$, Jones $R$, Vakil $N$, Junghard $O$, Lind $T$, Wernersson $B$, et al. Limited ability of the proton-pump inhibitor test to identify patients with gastroesophageal reflux disease. Clin Gastroenterol Hepatol 2012; 10: 1360-1366. [CrossRef]

13. Grande $M$, Sileri $P$, Attinà $G M$, De Luca $E$, Ciano $P$, Ciangola $\mathrm{Cl}$, et al. Nonerosive gastroesophageal reflux disease and mild degree of esophagitis: Comparison of symptoms endoscopic, manometric and pH-metric patterns. World J Surg Oncol 2012; 10: 84. [CrossRef]

14. Armstrong D. A critical assessment of the current status of nonerosive reflux disease. Digestion 2008; 78: 46-54. [CrossRef]

15. Holtmann G. Reflux disease: the disorder of the third millennium. Eur J Gastroenterol Hepatol 2001; 13: 5-11.

16. Fass R, Fennerty MB, Vakil N. Nonerosive reflux disease current concepts and dilemmas. Am J Gastroenterol 2001; 96: 303-314. [CrossRef]

17. Carlsson R, Dent J, Watts R, Riley S, Sheikh R, Hatlebakk J, et al. Gastrooesophageal reflux disease in primary care: an international study of different treatment strategies with omeprazole. International GORD Study Group. Eur J Gastroenterol Hepatol 1998; 10: 119-124. [CrossRef] 